\title{
Para ler Bertha Lutz
}

\author{
Lia Gomes Pinto de Sousa \\ Mariana Moraes de Oliveira Sombrio \\ Maria Margaret Lopes**
}

Bertha Maria Julia Lutz (1894-1976) é um ícone da historiografia feminista no Brasil. O seu feminismo dos anos 20-30, já foi rotulado como de elite, conservador, bem comportado, jurídico-institucional, senão mais do que isso. Sem a preocupação de rotulá-lo, temos lido e relido a trajetória indissociavelmente feminista / científica / política de Bertha, imersa na cultura de sua época. Uma época de valorização no país das atividades científicas, educacionais, de institucionalização das profissões acadêmicas e de progressiva busca por sua maior internacionalização, com forte referência aos Estados Unidos.

Temos interpretado Bertha Lutz sabendo que as leituras mais sensíveis de um texto são também argumentos situados sobre campos de significado e de poder. ${ }^{1} \mathrm{E}$ como entrar criticamente em competição por interpretações é uma prática também fundamental para os estudos das mulheres, nossa leitura

\footnotetext{
" Trabalho realizado no âmbito do projeto temático "Gênero, Corporalidades" (FAPESP, processo n 03/13691-0) coordenado por Mariza Corrêa.

*** Lia Gomes P. Sousa é historiadora e bolsista CNPq do PAGU-Unicamp; Mariana M.O. Sombrio é historiadora mestranda pelo DPCT-IG-Unicamp, e Maria Margaret Lopes é professora livre-docente do IG-Unicamp e pesquisadora do PAGU-Unicamp, Campinas-SP, Brasil. Agradecemos à bolsista de Iniciação Científica (CNPq/SAE-Unicamp), Carla Mecia P. Moraes, que durante o $2^{\circ}$ semestre de 2004 foi responsável pelo início do tratamento e análise da documentação jurídica de Bertha Lutz. lopssousa@yahoo.com.br

1 Haraway, Donna J. Simians, Cyborgs and Women. The Reinvention of Nature. London, Free Association Books, 1991.
} 
Documento

dos textos de Bertha Lutz, como tantas outras, está longe de ser ingênua. Está longe também de qualquer proposta de reinterpretação da história original, para escrevê-la bem de uma segunda vez. Nas leituras que temos feito, as mais prazerosas: têm sido as dos inúmeros documentos, em sua imensa maioria inéditos, sobre os mais variados temas, depositados em diferentes arquivos. De cada documento emergem inusitadas propostas de feminismos, que questionam o funcionamento do conceito como indefinido e por isso universalmente compreendido, estável, gerador de sentimentos consensuais. ${ }^{2}$

Quando Bertha Lutz fundou a FBPF, Federação Brasileira pelo Progresso Feminino, em 1922, pretendia, entre outras coisas, promover a educação e profissionalização das mulheres. Entre práticas e discursos transpostos, graduou-se em Ciências Naturais na Sorbonne, em 1918; em Direito no Rio de Janeiro, em 1933; consolidou sua carreira científica nos mais de 40 anos de funcionalismo público no Museu Nacional; liderou a luta pelo voto feminino e exerceu, ela própria, o direito de ser votada. No Parlamento propôs inúmeras mudanças na legislação brasileira. Os documentos que publicamos a seguir se referem a essa atuação que se deu em um curto período da vida de Bertha. Estes documentos que reproduzimos são dos arquivos do Museu Nacional. ${ }^{3}$

Bertha assumiu a cadeira de Deputada Federal em 28 de julho de 1936 e exerceu o mandato até 10 de novembro de 1937, quando o Congresso foi fechado por Getúlio Vargas, iniciando a ditadura do Estado Novo. Candidata nas eleições de 1934 pelo Partido Autonomista do Distrito Federal, representando a "Liga Eleitoral Independente" fundada pela FBPF, Bertha consegue

2 ScotT, Joan W. A invisibilidade da experiência. Projeto História (16), PUC-SP, São Paulo, fev. 1998. pp.297-325

3 Todo o Fundo Bertha Lutz encontra-se ainda em fase de organização no setor de documentação do Museu Nacional. Também por isso agradecemos especialmente Maria José Veloso e os demais funcionários pela cessão desse documento. 
apenas a suplência, mas assume o cargo substituindo o Deputado Cândido Pessoa, que viera a falecer. Antes de ingressar na Câmara, Bertha participara da Comissão Preparatória do Anteprojeto da Constituição (promulgada em 1934), reunida em Petrópolis em 1932. Muitas de suas proposições, que estão compiladas na obra 13 Princípios Básicos de Direito Constitucional, editada pelo Departamento de Estudos Jurídicos da FBPF, foram aceitas pela Constituinte $e$ incorporadas à legislação brasileira. As sugestões, muitas das quais já vinham sendo discutidas nos congressos feministas anteriores, defendiam os direitos políticos e jurídicos das mulheres em geral, dando especial atenção às questões relativas ao trabalho, à educação, à maternidade e à infância.

Durante um ano e três meses de atuação parlamentar, Bertha Lutz mesclou os interesses feministas com os próprios de sua formação científica, experiência profissional e situação funcional. No Plenário discursou sobre a transmissão da Lepra associada ao mosquito indicado pelas pesquisas de seu pai, Adolpho Lutz, e sobre o combate à Malária no então Distrito Federal. ${ }^{4}$ Mesmo nos 13 Princípios Básicos, considera também as questões referentes aos monumentos naturais, à proteção da natureza e à conservação da flora e fauna do país. E quando trata dos direitos femininos, muitas vezes seus argumentos são baseados em metáforas claramente naturalistas.

O documento que aqui publicamos é introduzido por um pequeno texto informando que Bertha apresentou uma série de emendas a um projeto de "reajustamento" do funcionalismo para o Ministério da Educação e Saúde Pública. Citando alguns destaques, aponta: as emendas que defendem os direitos adquiridos por concurso, direitos de alguns cargos científicos e do funcionalismo em geral; uma que se justifica na defesa do lar e da família, impedindo a transferência de funcionários casados para

4 Arquivo Nacional. Fundo/coleção Federação Brasileira pelo Progresso Feminino. Cx. 11. 
Documento

localidades diferentes; algumas que se mostram propriamente "em defesa dos direitos femininos", mais especificamente das mulheres trabalhadoras; e outras que são "de interesse das repartições científicas federais e seu pessoal".

Tais propostas, indicando interesses variados, remetem às múltiplas facetas de Bertha assumidas ao longo de sua trajetória. Além da Deputada Federal, está presente aqui uma mulher diplomada em Direito (campo em que talvez tenha se aventurado para atuar com melhor desempenho na luta feminista) cientista, funcionária pública, concursada para ingressar no Museu $\mathrm{Nacional}^{5}$, além da líder feminista.

Para o caso das emendas sobre a mulher funcionária, o documento indica o apoio de todos os membros da Comissão Especial Elaboradora do Estatuto da Funcionária Pública. Outrora descrita como "patrocinadora de uma reforma total da legislação brasileira que colocaria a mulher em condições de Senhora de si mesma"6, Bertha propôs a criação do Estatuto da Mulher com Carlota P. de Queiroz e, sem o apoio de Carlota, propôs a criação do Departamento Nacional da Mulher e do Departamento Nacional de Trabalho Feminino, Maternidade, Infância e Lar.

No âmbito dessas emendas, apresentamos a "Justificação" de uma delas que busca assegurar a "preferência às mulheres habilitadas para a orientação e fiscalização dos serviços referentes ao trabalho feminino, ao lar, à maternidade e infância" (art. 121 da Constituição Federal)", na qual Bertha reforça uma proposta sua já apresentada desde o Anteprojeto. De fato, entre os itens propostos por Bertha e incluídos na Constituição de 1934 estão o direito de acesso das mulheres a funções públicas e à direção $e$

${ }^{5}$ Bertha prestou concurso público em 1919 para ingressar no Museu Nacional. Embora o cargo conquistado fosse de "Secretário", desde cedo começou a atuar como naturalista. E ao final de sua vida, acumulou diversas especialidades e habilitações como Botânica, Zoologia e organização de Museus.

6 A.N. Fundo/coleção FBPF. Cx. 11. 
Bertha Lutz

administração de programas de assistência e bem-estar social relativos à maternidade $e$ à infância. ${ }^{7}$

A "Justificação" dessa emenda trata de um assunto que aborda não só os direitos da mulher funcionária, mas, mais especificamente, da atuação feminina na área da Saúde. Argumenta sobre a legitimidade do Serviço de Enfermagem da Diretoria Nacional de Saúde Pública e Assistência Médico Social estar sob a direção, administração e execução prática de mulheres habilitadas. Por um lado, assegura que reside aí a essência desse Serviço, e o que garantiria o sucesso e reconhecimento deste que representa "uma das modalidades mais modernas e eficientes da Administração Pública existentes no Brasil".

Valendo-se de um discurso quase evolucionista, Bertha afirma que sua forma de organização equipara-se aos países de "civilização adiantada" e, ela mesma dotada da autoridade do saber científico, enaltece a "clarividência dos grandes luminares da ciência" que contribui para elevar o padrão de saúde e, por fim, de desenvolvimento do Brasil. O reconhecimento dos higienistas do exterior e da Rockfeller Foundation evidencia seu entendimento de que a organização e direção feminina estariam em dia com os ideais da modernidade e do progresso, dos quais países como os Estados Unidos, Canadá e Inglaterra eram exemplos.

A notoriedade científica inconteste de Carlos Chagas é usada como argumento de autoridade para reforçar a importância e respeito ao Serviço de Enfermagem. O sanitarista é apresentado como criador da organização que idealizara "dentro da moldura da enfermagem técnica moderna". Por fim, numa visão organicista, a Superintendência feminina e outros cargos de chefia são apontados como a "cabeça", órgão vital da instituição contra qual seria desfechado um golpe caso fossem extintos.

7 BESSE, Susan. Modernizando a desigualdade. Reestruturando a ideologia de Gênero no Brasil. São Paulo, EDUSP, pp.189-90. 
Documento

Bertha, por outro lado, baseia-se no direito constitucional garantido no artigo que assegura a preferência por mulheres para atuarem nos serviços que dizem respeito ao trabalho da mulher. $\mathrm{E}$ nesse momento seu discurso associa a Enfermagem a uma atividade naturalmente feminina, uma aplicação prática $e$ científica do que seria um "instinto maternal" intrínseco à mulher.

Ora, desde os tempos mais remotos, desde os primórdios do cristianismo, até o surgimento de Florence Nightingale na guerra da Criméia, e de Ana Nery no Brasil, a enfermagem foi sempre vocação feminina reconhecida como tal. Não é outra a orientação da Ciência Médica moderna que insiste na conservação da profissão da enfermagem em mãos femininas, habilitando-as para o exercício dessa maternidade espiritual, por preparo técnico rigoroso. (grifo nosso)

Resgatando a história da enfermagem é possível perceber que, ao contrário do pensamento essencialista de Bertha Lutz, a atribuição dessa profissão a uma natureza feminina data de fins do século XIX. De fato, as mulheres tiveram uma importante participação na formação da Enfermagem moderna, mas anteriormente ao seu advento, tanto homens como mulheres praticavam esse tipo de atividade. Na passagem do século XIX para o século XX, acentua-se a divisão entre espaço público $e$ privado. As mulheres, confinadas aos cuidados do lar, "possuíam" as aptidões necessárias para a prática da enfermagem - atividade que, exposta à esfera pública, aplicava muitos dos conhecimentos adquiridos pela função doméstica. Talvez por isso tenha sido um dos primeiros espaços públicos ocupados pelas mulheres, e que Bertha Lutz defendeu com tanto afinco neste documento em especial. Na emenda propõe que "restabeleça-se o cargo de Superintendente Geral do Serviço de Enfermagem" $e$ a substituição do título de "Enfermeiro" pelo de "Enfermeira Técnica". 
Em suas palavras, uma denúncia contra a destituição do Serviço Nacional de Enfermagem da sua Superintendência feminina e outros cargos de chefia:

É um atentado contra o único serviço público que até agora foi dado à mulher brasileira organizar e que constitui uma promessa alviçareira da colaboração feminina eficiente no progresso do país.

A visão essencialista acerca das aptidões femininas que se constituiu em fins do século XIX, sob a influência de um discurso médico, atribuía diferentes capacidades aos homens e mulheres de acordo com suas características fisiológicas. Apoiando sua retórica aqui nessa concepção, que em outros textos parece negar, Bertha Lutz apresentou na Câmara uma estratégia para garantir uma possibilidade de profissionalização às mulheres. Neste contexto ela escreveu sobre a enfermagem, profissão da área da saúde pública, questão tão debatida e importante nesse período de modernização. Nesse momento, a ciência atuava como carrochefe guiando as teorias higienistas e sanitaristas que estiveram presentes também no pensamento de Bertha Lutz, mostrando como as mulheres poderiam contribuir para um progresso não questionado do país. 
Documento

\section{Transcrição do documento}

\section{Câmara dos Deputados [logotipo]}

A deputada Bertha Lutz apresentou uma série de emendas ao reajustamento, visando salvaguardar os direitos da mulher funcionária do funcionalismo em geral $e$ interesses de várias repartições científicas. Entre estas emendas se destacam:

Uma que salvaguarda os direitos adquiridos por concurso; uma que excetua os cargos científicos de direção e magistério da proibição de acumulação. Esta emenda se baseia em exceção textual da Constituição (art.172 $\S 1^{\circ}$.); Outra que efetiva os contratados com mais de 10 anos de serviço sendo também baseada no texto constitucional (art.170) - Apresentou também a deputada Bertha Lutz uma emenda que impede a diminuição dos vencimentos atuais.

Outra emenda da deputada autonomista providencia no sentido de não desagregar lares pela transferência de funcionários casados para localidades diferentes, impossibilitando-lhes a vida em comum.

As emendas da deputada Bertha Lutz em defesa dos direitos femininos asseguram à mulher representação no Conselho de Funcionários e insistem na aplicação a casos concretos dos artigos da Constituição por ela defendidos desde o ante-projeto. São eles os artigos que proíbem diferenças de vencimentos baseados no estado civil e no sexo e dão preferência às mulheres habilitadas para a orientação e fiscalização dos serviços referentes ao trabalho feminino, ao lar, à maternidade e infância. (art.121 da Constituição Federal).

As outras emendas da deputada Bertha Lutz são de interesses das repartições científicas federais e seu pessoal. Algumas dessas emendas foram assignadas por numerosos colegas para esse fim convidados pela deputada Bertha Lutz.

As emendas que visam o interesse da mulher funcionária trazem as assinaturas de todos os membros da Comissão Especial 
elaboradoras do Estatuto da Funcionária Pública recentemente criada pela Câmara, por iniciativa da deputada Bertha Lutz.

\section{PROJETO 255 \\ EMENDAS}

Ministério de Educação e Saúde Pública

I - Restabeleça-se o cargo de:

Superintendente Geral do Serviço de Enfermagem com a denominação de Superintendente na classe $\mathrm{M}$.

(localizando ou na pág. 2 do quadro 1 logo após o Inspetor de Informações, Propaganda e Educação Sanitária ou na pág. 12 Carreira Enfermeiro)

II - Uniformize-se o cargo de Diretora de Divisão de Saúde Publica (pág. 12) Enfermeiro classe J com o da Diretora da Escola de Enfermeiras Anna Nery (pág. 3) com a denominação de Directora na classe $\mathrm{K}$.

III - Restabeleça-se: a secretária estenógrafa do Serviço de Enfermagem e a secretária estenógrafa da Escola Anna Nery com a denominação de oficial administrativo classe I.

IV - Substitua-se o título de Enfermeiro (pág. 12) pelo de Enfermeira Técnica.

V - onde diz: 100 alunas internas (pág. 55) a 1:200\$000 cada uma diga-se: 100 alunas a 1:440\$000 cada uma.

VI - onde diz (pág. 51) 2 mordomas, classe G, diga-se três mordomas. 
Documento

\section{JUSTIFICAÇÃO}

O Serviço de Enfermagem da Diretoria Nacional de Saúde Pública e Assistência Médico Social representa uma das modalidades mais modernas e eficientes da Administração Pública existentes no Brasil. Como o Instituto Oswaldo Cruz e mais algumas instituições modelares, devidas à clarividência de grandes luminares da ciência, tem concorrido para a eficiência do combate às doenças e para a elevação do padrão de saúde do povo brasileiro. Pela forma de sua organização, idêntica àquela que existe nos Estados Unidos, no Canadá, na Inglaterra e outros países de civilização adiantada, que possuem os índices mais elevados de organização de enfermagem técnica, muito concorre para elevar o renome do Brasil no exterior.

É obra do inolvidável cientista Prof. Carlos Chagas, cuja orientação era tida em tão alto apreço não só em Minas, sua terra natal e no Brasil, como no estrangeiro, que depois de ter ele reorganizado o Departamento de Saúde Pública foi eleito e mantido até a sua morte no Conselho Pan-americano de Saúde Pública e no Conselho Sanitário da Sociedade das Nações.

Ora a essência desse serviço, tal qual Carlos Chagas o organizou, dentro da moldura da enfermagem técnica moderna, reside na sua direção, administração e execução prática por mulheres, habilitadas, por longo tirocínio de estudos científicos e práticos, em Escolas, que como vestibular exigem diploma de curso secundário, tal qual as faculdades e outras Escolas Superiores Universitárias.

A forma de organização e direção feminina do Serviço de Enfermagem despertou de tal modo o interesse dos higienistas no exterior, que a Rockfeller Foundation, instituição internacional dedicada ao progresso da Medicina e da Higiene, não hesitou em oferecer colaboração estreita ao Prof. Carlos Chagas. Premiou a atual Superintendente, a primeira aluna que ingressou na enfermagem técnica brasileira, com bolsa de viagem, para que em longo curso de especialização, adquirisse o preparo técnico de 
Superintendente na Escola de Enfermeiras da Universidade de Pensylvania e visitasse instituições congêneres nos Estados Unidos e em outros paizes.

Acresce ainda que a Constituição Brasileira, ao art. $121 / 3^{\circ}$, estabelece, textualmente, a preferência às mulheres habilitadas para a orientação dos serviços que dizem respeito ao trabalho da mulher. Ora, desde os tempos mais remotos, desde os primórdios do cristianismo, até o surgimento de Florence Nightingale na guerra da Criméa, e de Anna Nery no Brasil, a enfermagem foi sempre vocação feminina reconhecida como tal. Não é outra a orientação da ciência Médica moderna que insiste na conservação da profissão de enfermagem em mãos femininas, habilitando-as para o exercício dessa maternidade espiritual, por preparo técnico rigoroso.

Destituir o Serviço Nacional de Enfermagem e Assistência Social na hora em que os Estados começam a organizá-lo da sua Superintendência feminina e outros cargos de chefia $e$ de administração técnica especializada, é torná-la acéfala, mutilá-la, equivale ao primeiro passo na sua destruição.

Constitui um golpe desfechado contra a memória do eminente brasileiro Carlos Chagas, desmoronando o serviço que constituiu o seu maior orgulho de sanitarista, mal decorrido um ano de seu falecimento prematuro e inditoso para a ciência e para o Brasil. Desmerece a nossa organização sanitária aos olhos da organização sanitária mundial.

É um atentado contra o único serviço público que até agora foi dado à mulher brasileira organizar e que constitui uma promessa alvissareira da colaboração feminina eficiente no progresso do país.

Mais ainda, importa em violação flagrante da Constituição. 